\title{
Possibility of Using Flexible Dentures Over Iliac Bone Graft in Adolescent Patients With Ameloblastoma: A Case Report
}

Ammar Belal ( D Dr.ammar.belal@gmail.com)

University of Hama https://orcid.org/0000-0002-1888-5148

Bassil Monther

University of Hama https://orcid.org/0000-0001-7803-4882

Wael Alzarif

Dental Clinic

\section{Case report}

Keywords: Ameloblastoma, bone graft, flexible denture, interim prosthetic

Posted Date: October 18th, 2021

DOI: https://doi.org/10.21203/rs.3.rs-960275/v1

License: (c) (i) This work is licensed under a Creative Commons Attribution 4.0 International License.

Read Full License 


\section{Abstract}

\section{Background}

The use of bone grafts is a common procedure after excision and reconstruction of the mandible, but it is rare in children and adolescents due to incomplete growth, which means a long transition period until reaching an appropriate age for implantation or predictable outcomes.

\section{Case Presentation}

This article describes 9 months follow-up of the use of a flexible denture above a bone graft taken from the anterior iliac crest for adolescent Patients with resected mandible due to ameloblastoma.Taking into account prosthetic considerations, radiography, and clinical monitoring, showed no problems with the graft.

\section{Conclusion}

It is safe to use a flexible denture as prosthetic over lliac bone graft block during healing period.

\section{Background}

Ameloblastoma is a rare tumor, but it affects all ages, especially between the second and fifth decade, and equally, in both sexes, its incidence in the lower jaw is $80 \%$ compared to the upper jaw, Although it is a benign tumor, it has a pandemic effect because it grows without symptoms and tends to be recurrent in $90 \%$ of conservative approach (enucleation, marsupialization, or curettage $0^{1-4}$. Therefore to get the best results 1 to $2 \mathrm{~cm}$ of healthy bone around the tumor must be excised, whatever its type (multicystic, perpheral, and unicystic tumors ${ }^{5-7}$. This excision may lead to a dramatic collapse of the patient's swallowing, pronunciation, chewing and aesthetic functions and the loos of anatomical structures will make the Procedures of prosthetics difficult, especially in cases of the lower jaw, in addition to the deviation of the remaining segment toward the defect side which may result in the loss of occlusal contact on the defect side and a shift in the posterior functional contacts on the normal side ${ }^{8,9}$. therefore, expeditiously rehabilitation after marginal or segmental mandibulectomy is preferred ${ }^{10,11}$. There are many techniques for management of mandibular continuity defects such as Nonvascularized bone Graft, Iliac crest free flap, vascularized osseous free graft..etc ${ }^{12}$ and whatever the donor site is (The fibula, scapula, rib, and the iliac crest) ${ }^{13}$, it is desirable to preserve the bone graft until full healing to make the Final prosthetic whatever its types including implant-supported fixed prostheses ${ }^{14}$, or removable Dentures Whether supported by implants or not ${ }^{15,16}$, but until then, the bone graft must be

protected In addition to help the patient during this stage to restore the masticatory, verbal and aesthetic function, and to improve his psychological state through the interim 
prosthesis, Which is mostly a removable denture. However interim care is not indicated for mandibular defects in most cases and discussions usually talk about maxillary ones unless have to wait for the surgical site to heal and is dimensionally stable ${ }^{17,18}$. Many studies describe the factors influencing the success or failure of bone grafts especially those related to surgery or post-surgery procedures like (Type of defect and scope of excision, bone graft, Infection, Extrusion, Malocclusion, Facial nerve involvement, Deformation of lower face..etc) ${ }^{19-20}$, while factors related to the prosthetics are studied extensively in terms of its effect on alveolar bone resorption in conventional cases, such as its type, design, method of impressions and scheme of occlusion ${ }^{21-25}$. Prosthodontic considerations were mentioned in articles and references about acrylic and hybrid prosthetics due to their ability to be modified with an interim or resin lining material, also talked about their design such as not extending the base widely as normal dentures or reducing the occlusal surface and The use of existing teeth for additional fixation in metal or acrylic dentures ${ }^{18,26-28}$, But it is rare to find an article about using the flexible dentures maybe because The controversy about it is not over yet, But it is still a viable option of all kinds (Polyamide, Polyester, Acrylic resin, Polycarbonate and Polypropylene), in addition to having many useful advantages and indications as interim dentures or spare dentures for patients with metal allergy or for whom esthetics must be given top priority ${ }^{29}$. The purpose of this clinical report is to descride the Possibility of using interim flexible acrylic dentures over lliac bone graft for a considerable period in cases of mandibular resection in adolescent patients with ameloblastoma.

\section{Case Presentation}

A 12 years old male patient reported to the department of oral and maxillofacial surgery at the national hospital of Hama with visible swelling, intraorally there was a noticeable expansion of the mandible body In the posterior section, After the radiographic examination

it was suspected that the presence of multicystic Ameloblastoma (Fig 1), which was confirmed by histological examination. On cbct scan, the tumor was extending from the tooth 34 to 38 with part of the ramus. According to (ord et all) ${ }^{30}$, the treatment of ameloblastoma would be complicated

because of continued growth and a higher percentage of cancellous bone which increased bone turnover and high periosteal reactivity, so the treatment should be in the same way used with adults, so a partial resection of the mandible from the tooth 33 Until the ramus was done while keeping the condyle (Fig 2).

A titanium reconstruction plate was adapted and contoured to mandible body to reinforce and help stabilize a nonvascularized block graft which was taken after8 months if the first surgery from the

anterior iliac crest and Because the patient's bone is spongy and fragile, it was waited a whole year to confirm the success of the graft and the stability of its dimensions, during this period a transpalatal arch was applied to prevent rotation of upper molars and maintain the arch width,

(Fig 3)(Fig 4). 
The second stage of treatment was involved a removable partial denture Until the growth and calcification of the bone is complete to place implants and fixed prosthetic.

Intraoral examination showed an obvious volume of soft tissue in the graft region which had healed well (Fig 5). All options were discussed with the patient parents and their finance and expectation, They refused to perform another surgical procedure to remove the flabby soft tissue. Prosthodontic plan was designed for the fabrication of a flexible partial Denture.

As usually the procedures began with making a primary impression using Irreversible Hydrocolloids material, The custom tray was made by auto polymerizing acrylic resin (Simplex Hi, Kemdent, UK) and checked in the patient mouth and to fill the missed area in the tray of the resected mandible, impression compound sticks (Kerr, Italy) were used to support the final impression material and to make a functional impression which was made with Irreversible Hydrocolloids material(Zeta plu, Zhermak, Italy) and poured with the pink gypsum type IV (Shera, Italy), (Fig 6).

The relationship was registered using a register plate made with auto polymerizing acrylic resin and modeling wax(Tenatex, Kemdent, UK) to make the rim that hold the medium (chemi sil bite, Hyvincare, Korea), taking into account the situation of the mandible and its deviation. This stage is considered critical so the relationship was manually directed until reaching the most stable position, taking advantage of the remaining teeth on the natural side Then confirmed during the clinical trial. The denture was processed With flexible acrylic resin (valplast, Tinjin iris, china). the denture was delivered to the patient after assessment for the speech, mastication, and adjustment procedures (Fig 7)(Fig 8), The teeth were prepared according to class I of Black and restored with an amalgam filling to create a natural look for a young man of this age. A digital panoramic radiograph was made on the same day with a silicone bite on the biting block of the radiographic device to ensure that the patient bites the same situation after the end of the observation period which was 9 months, (Fig 9).

\section{Discussion}

The initial plan chosen for this patient was a flexible partial denture which will be used for a considerable period. All options for the type of the Removable partial denture have been taken into account, Starting with the cast metal one, But it is not considered a logical option due to the incomplete growth of young people and the high price of it, especially because there is the possibility of making a new denture after a while and leaving him without a denture in this age is also illogical because the need for restoring the mastication and cosmesis in addition to the possibility of food trapping and Possible infections of the surgical area due to the difficulty cleaning and impaired neuromuscular function ${ }^{17}$. The second option was a heat polymerizing resin denture as an interim prosthetic due to its cheap price and lining capacity, however the presence of a large volume of flabby tissue and difficulty to obtain sufficient stability or the possibility of damage to adjacent teeth and the health of supporting soft tissues ${ }^{17}$, especially above the graft area make the flexible denture more acceptable choice or several reasons: 
- Its flexibility allows obtaining additional stability and retention by increasing the flange extension under hard or soft tissue undercuts, in addition to extending the clasp of more teeth ${ }^{24,29}$.

- softer surface compared with acrylic resin meaning that patients feel better when worn and appear to be no problem with the fit ${ }^{24,29}$.

- Thermoplastic resins have hygienic advantages due to their low water absorption and solubility ${ }^{24}$.

- Aesthetically is better than acrylic resin ${ }^{24}$.

Taking into account some of its disadvantages Such as difficulty to repair or poor resistance to scratching ${ }^{24}$, alerting him the need to take care of oral health and regular reviews. To reduce the functional efforts transferred to the graft by reducing the Total Occlusal load applied in the supporting tissue, the lingualized articulation at the premolars was adopted but anatomic one at first molar For more effective chewing but With the deletion of the second molar $^{17,24}$.

Panoramic imaging is an accepted procedure for observing vertical changes in the bone ${ }^{31}$ which after nine months showed no bone resorption or not exceeded bone remodeling, (Fig 10).

besides the Intraoral examination showed healthy tissue with no wasting or any infection.

\section{Conclusions}

After a full nine months of observation of a bone graft taken from the anterior iliac crest under a flexible partial denture, adhering to Prosthetic considerations, It can be said that it is safe to use a flexible denture as prosthetic over lliac bone graft block during healing period.

\section{Declarations}

\section{Ethical Approval and Consent to participate:}

Ethical considerations regarding patient well-being and confidentiality was taken by the authors

\section{Consent for publication:}

Ethical approval for publication from the Dean of the Faculty of Dentistry in Hama.

\section{Availability of data and materials:}

All materials used are suitable for human use according to the recommendations of the World Health Organization.

\section{Competing interests:}


There is no conflict of interest with any pharmaceutical company, tool, person or contributor to this article.

\section{Funding:}

There is no funding from anyone but the practicing doctor himself or from the patient as clinic fees.

\section{Authors' contributions:}

Free scientific support and clinical advice.

\section{Acknowledgements:}

Thanks and appreciation For co-authors, Dr. Bassil Monther, Dr. Wael Al-Zarif.

Thanks for Dean of the College of Dentistry, Dr. Bassam Al-Najjar.

Appreciation For Prof. Dr Mohammad Y Hajeer And for the national Hospital in Hama And everyone who contributed to the success of this clinical case In addition, thanks to the Head and Face Medicine journal for accepting my request to publish this article.

Authors' information:

1- Ammar Belal,DDs, Msc:

Master's Degree, Clinical instructor, School of Dentistry, Hama University, Removable prosthodontic Department, Hama, Syria.

2- , Bassil Monther, DDS, Phd:

Professor, Doctorate degree, School of Dentistry, Hama University, Removable prosthodontic Department, Hama, Syria.

3- Wael Alzarif, DDs, OMS:

Oral and Maxillofacial Surgery, Syrian Board of Medical Specialties, Head of Oral and Maxillofacial Surgery, National Hospital of Hama. Hama, Syria.

\section{References}

1. OOMENS, Marjolijn AE M.; VAN DER WAAL, Isaäc. Epidemiology of ameloblastomas of the jaws; a report from the Netherlands. Medicina oral, patologia oral y cirugia bucal, 2014, 19.6: e581.

2. NETTO, Rafael, et al. Rehabilitation with dental implants in microvascular iliac graft after solid ameloblastoma resection: a case report. Implant dentistry, 2013, 22.6: 561-565. 
3. KUMAR, S. Anil; SAHOO, Nand Kishore; SANDHU, Harbir Singh. Vascularised fibula osteocutaneous flap for mandibular reconstruction and multiple implant retained fixed prosthetic rehabilitation of a patient with mandibular ameloblastoma. Medical Journal, Armed Forces India, 2015, 71.Suppl 2: S534.

4. . MORENO-SORIANO, C., et al. Postsurgical Prosthetic Rehabilitation after Mandibular Ameloblastoma Resection: A 7-Year Follow-Up Case Report. Case Reports in Dentistry, 2021, 2021.

5. YOON, Hye-Jung, et al. Ameloblastic carcinoma: an analysis of 6 cases with review of the literature. Oral Surgery, Oral Medicine, Oral Pathology, Oral Radiology, and Endodontology, 2009, 108.6: 904913.

6. POGREL, M. A.; MONTES, D. M. Is there a role for enucleation in the management of ameloblastoma?. International journal of oral and maxillofacial surgery, 2009, 38.8: 807-812.

7. Philipsen HP, Reichart PA: Classification of odontogenic tumors and allied lesions. Odontogenic tumors and allied lesions. 2004, Quintessence Pub. Co. Ltd, 21-3.

8. BEUMER, John; CURTLS, Thomas A.; MARUNICK, Mark T. Maxillofacial rehabilitation prosthodontic and surgical considerations. Ishigaki Euroamerica, 1996. p143-4.

9. TAYLOR, T. D. Clinical maxillofacial prosthetics. Assessment, 2000, p 155-88.

10. PETROVIC, Ivana, et al. Oral rehabilitation for patients with marginal and segmental mandibulectomy: A retrospective review of 111 mandibular resection prostheses. The Journal of prosthetic dentistry, 2019, 122.1: 82-87.

11. LUSTOSA, Romulo Maciel, et al. Continuity resection of the mandible after ameloblastomafeasibility of oral rehabilitation with rhBMP-2 associated to bovine xenograft followed by implant installation. Journal of Cranio-maxillofacial Surgery, 2015, 43.8: 1553-1560.

12. FERNANDES, Rui P.; YETZER, Jacob G. Reconstruction of acquired oromandibular defects. Oral and maxillofacial surgery clinics of North America, 2013, 25.2: 241-249.

13. MEHTA, Ritvik P.; DESCALER, Daniel G. Mandibular reconstruction in 2004: an analysis of different techniques. Current opinion in otolaryngology \& head and neck surgery, 2004, 12.4: 288-293.

14. CAKAN, Umut; ANIL, Nesrin; ASLAN, Yavuz. Prosthetic rehabilitation of a mandibular gunshot defect with an implant-supported fixed partial denture: a clinical report. The Journal of prosthetic dentistry, 2006, 95.4: 274-279.

15. GÖKÇEN-RÖHLIG, Bilge, et al. Prosthetic rehabilitation of a patient with a mandibular defect caused by a gunshot wound. Journal of Craniofacial Surgery, 2009, 20.5: 1614-1617.

16. DE FREITAS, Renato, et al. Prosthetic rehabilitation of a bone defect with a teeth-implant supported, removable partial denture. Implant dentistry, 2006, 15.3: 241-247.

17. CARR, Alan B.; BROWN, David T. McCracken's removable partial prosthodontics-e-book. Elsevier Health Sciences, 2016, 31,232, 324-328, 330-336.

18. BEUMER III, John; MARUNICK, Mark T.; ESPOSITO, Salvatore J. Maxillofacial rehabilitation: prosthodontic and surgical management of cancer-related, acquired, and congenital defects of the 
head and neck. Quintessence Pub, 2011, 172.

19. CHEN, Shih-Heng, et al. Reconstruction for Mandibular Implant Failure. Issues in Flap Surgery, 2018, 103.

20. POGREL, M. A., et al. A comparison of vascularized and nonvascularized bone grafts for reconstruction of mandibular continuity defects. Journal of oral and maxillofacial surgery, 1997, 55.11: 1200-1206.

21. Belal A, D. D. S. Effect of the functional impression on the alveolar resorption beneath the flexible acrylic resin bases for the partial removable dentures patients of class I of Kennedy.

22. Aljammal A, In-vivo and in-vitro comparative study between removable partial dentures fabricated by using International Journal of Medical and Health Research 106.

23. Alisa $\mathrm{H}$, a comparative study between movable denture bases prepared by different methods and their effect on oral mucosa, 2007, 25.

24. ŞAKAR, Olcay (ed.). Removable partial dentures: a practitioners' manual. Springer, 2015,33-34,122125.

25. Jnaid F. Evaluation of three methods for management of Stress distribution of mandibular distal extention removable partial dentures-Kennedy class I-(in vivo and in-vitro study). 2015; 6998(157):158.

26. CANTOR, Robert; CURTIS, Thomas A. Prosthetic management of edentulous mandibulectomy patients. Part I. Anatomic, physiologic, and psychologic considerations. The Journal of prosthetic dentistry, 1971, 25.4: 446-457.

27. CANTOR, Robert; CURTIS, Thomas A. Prosthetic management of edentulous mandibulectomy patients. Part II. Clinical procedures. The Journal of prosthetic dentistry, 1971, 25.5: 546-555.

28. LEONG, Elvin WJ, et al. Management of acquired mandibular defects-prosthodontic considerations. Singapore dental journal, 2005, 28.1: 22.

29. FUEKI, Kenji, et al. Clinical application of removable partial dentures using thermoplastic resin-Part I: Definition and indication of non-metal clasp dentures. Journal of prosthodontic research, 2014, 58.1: 3-10.

30. ORD, R. A., et al. Ameloblastoma in children. Journal of oral and maxillofacial surgery, 2002, 60.7: 762-770.

31. ACHARYA, Samiksha; LOHE, V. K.; BHOWATE, R. R. Evaluation and comparison of alveolar bone loss of maxilla and mandible in completely edentulous patients on digital panoramic radiographs. J Oral Med, Oral Sur, Oral Path \& Oral Radio, 2016, 2: 112-119.

\section{Figures}




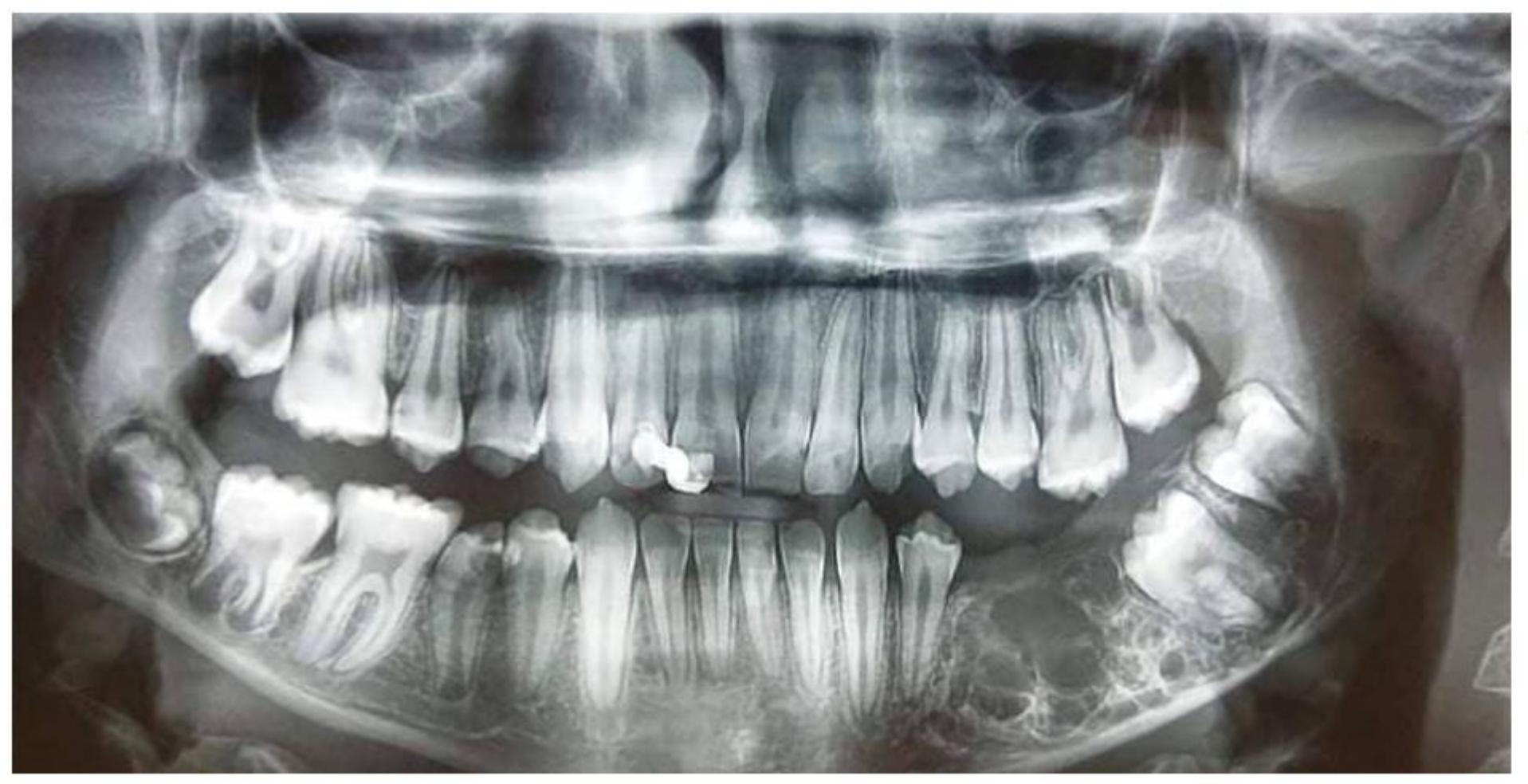

Figure 1

Preoperative panoramic radiograph. 


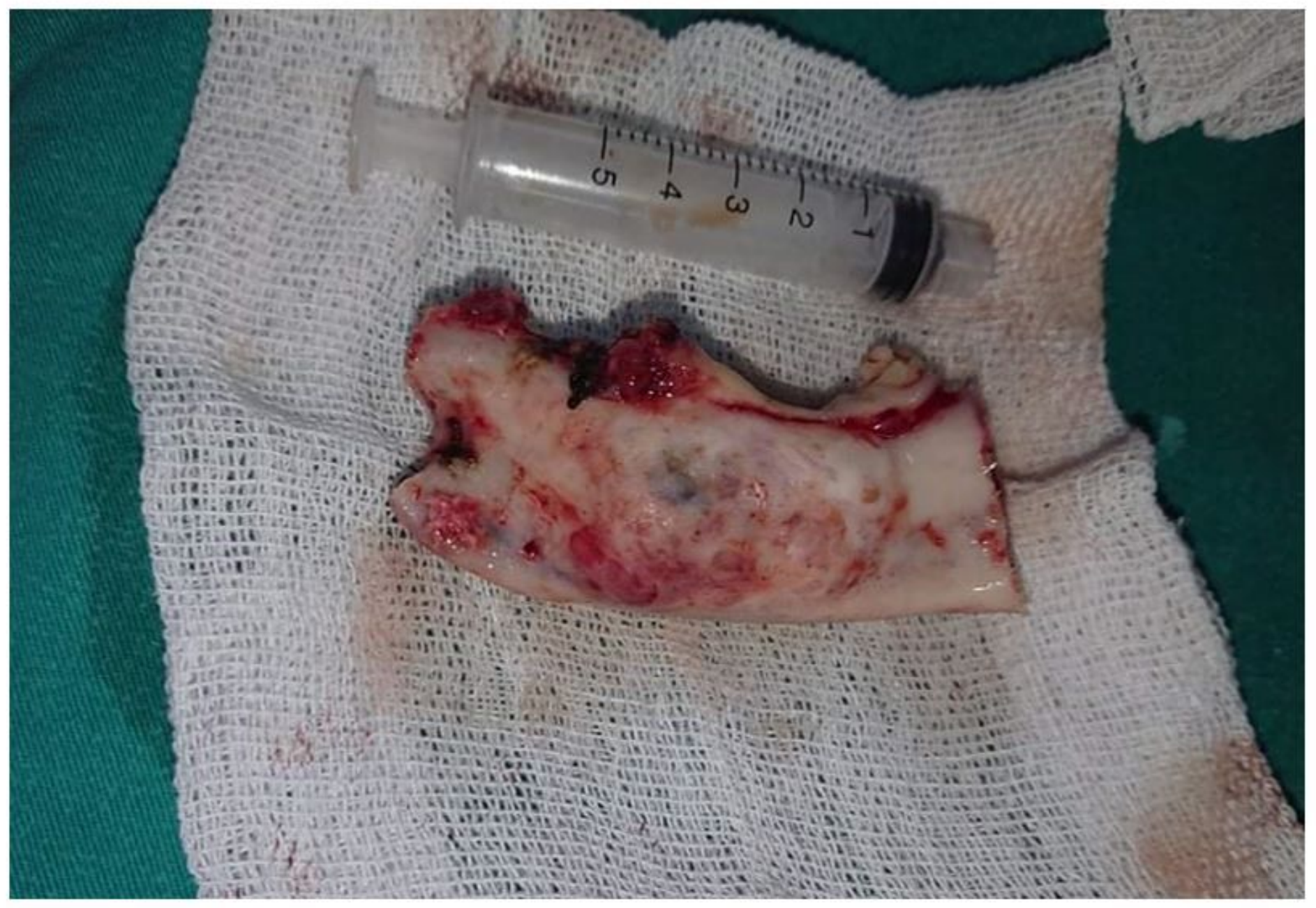

Figure 2

excised bone 


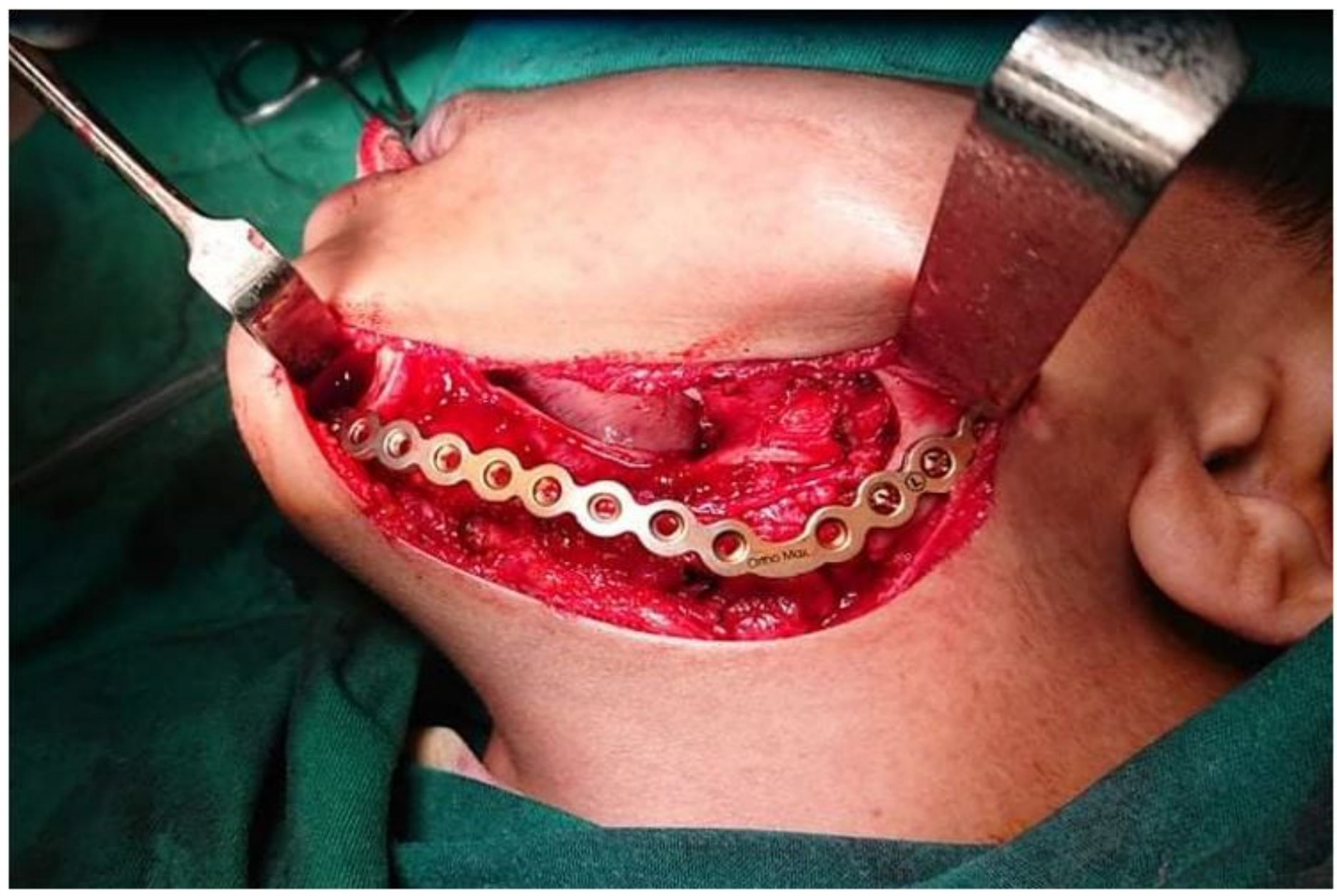

Figure 3

The titanium reconstruction plate 


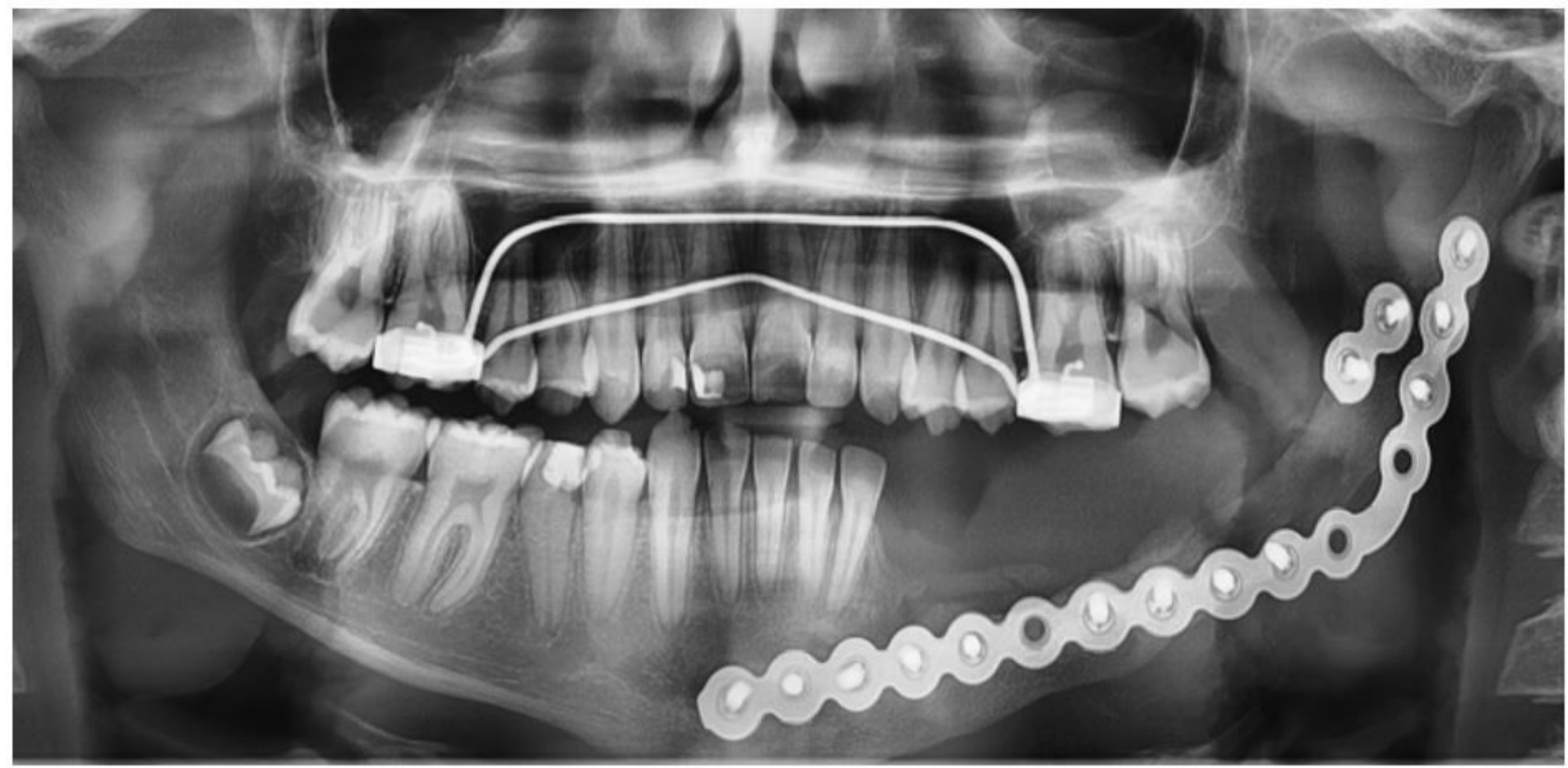

\section{Figure 4}

postoperative view with the Graft

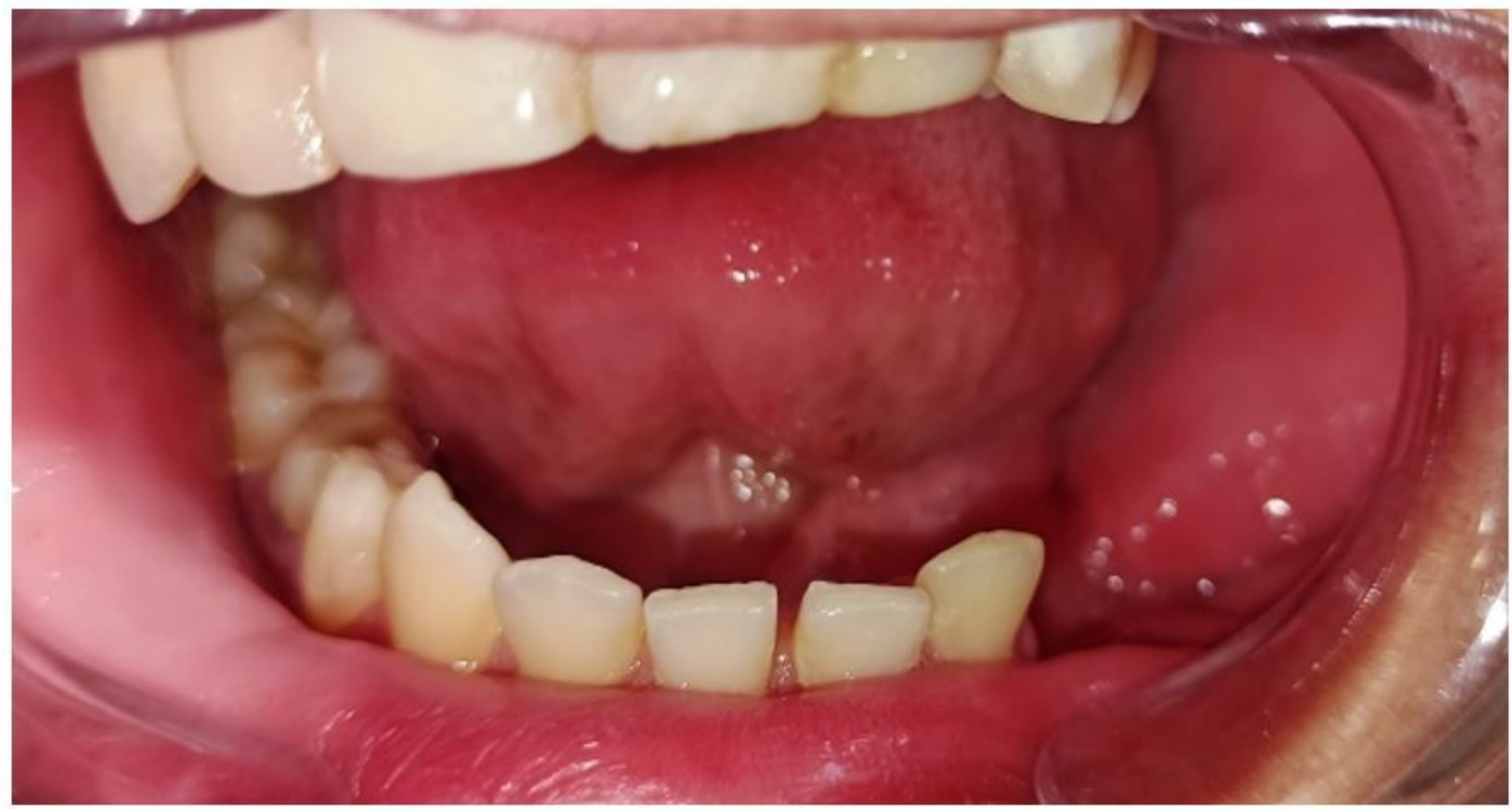

Figure 5

intraoral view. 


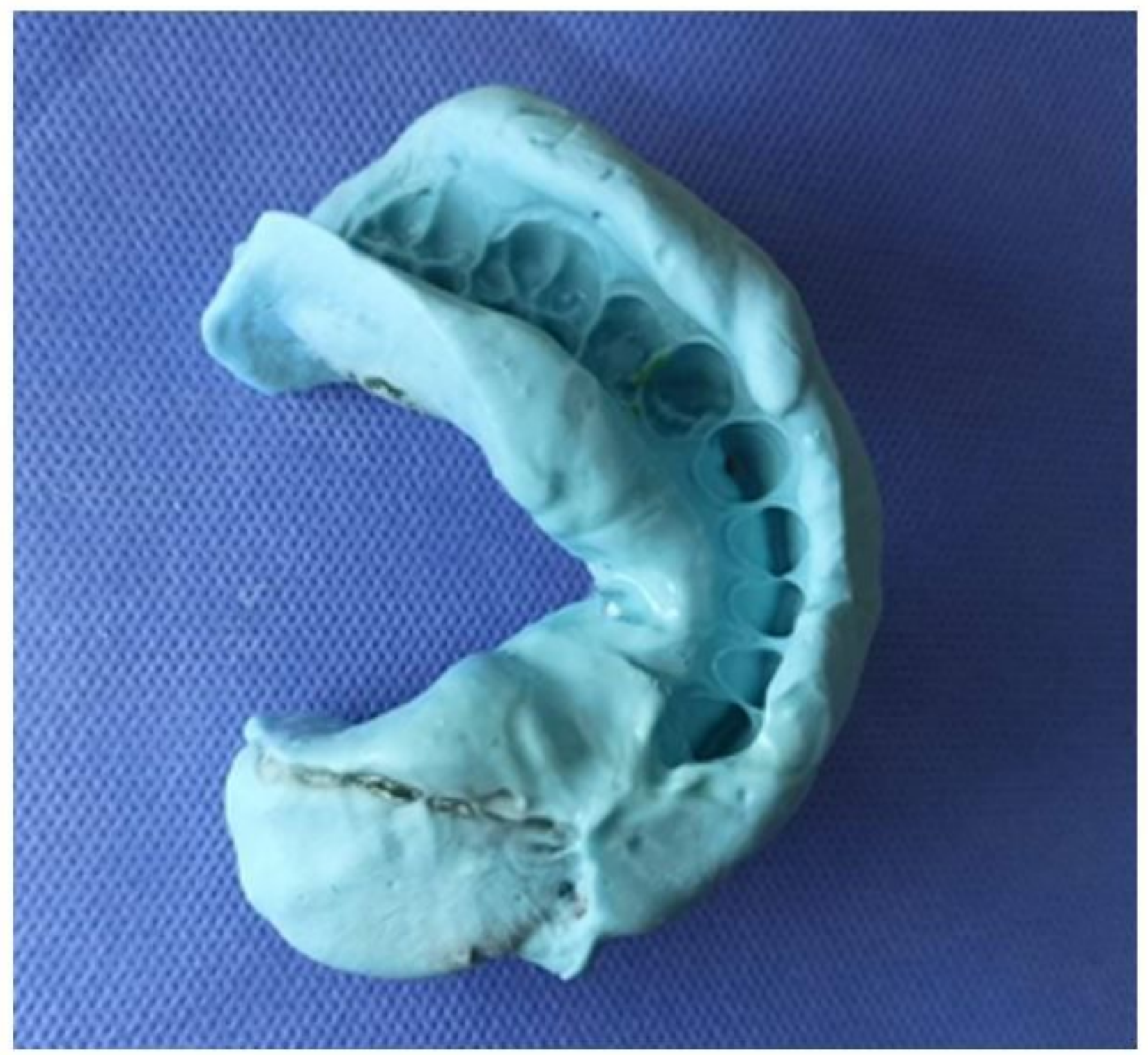

Figure 6

Final Impression 


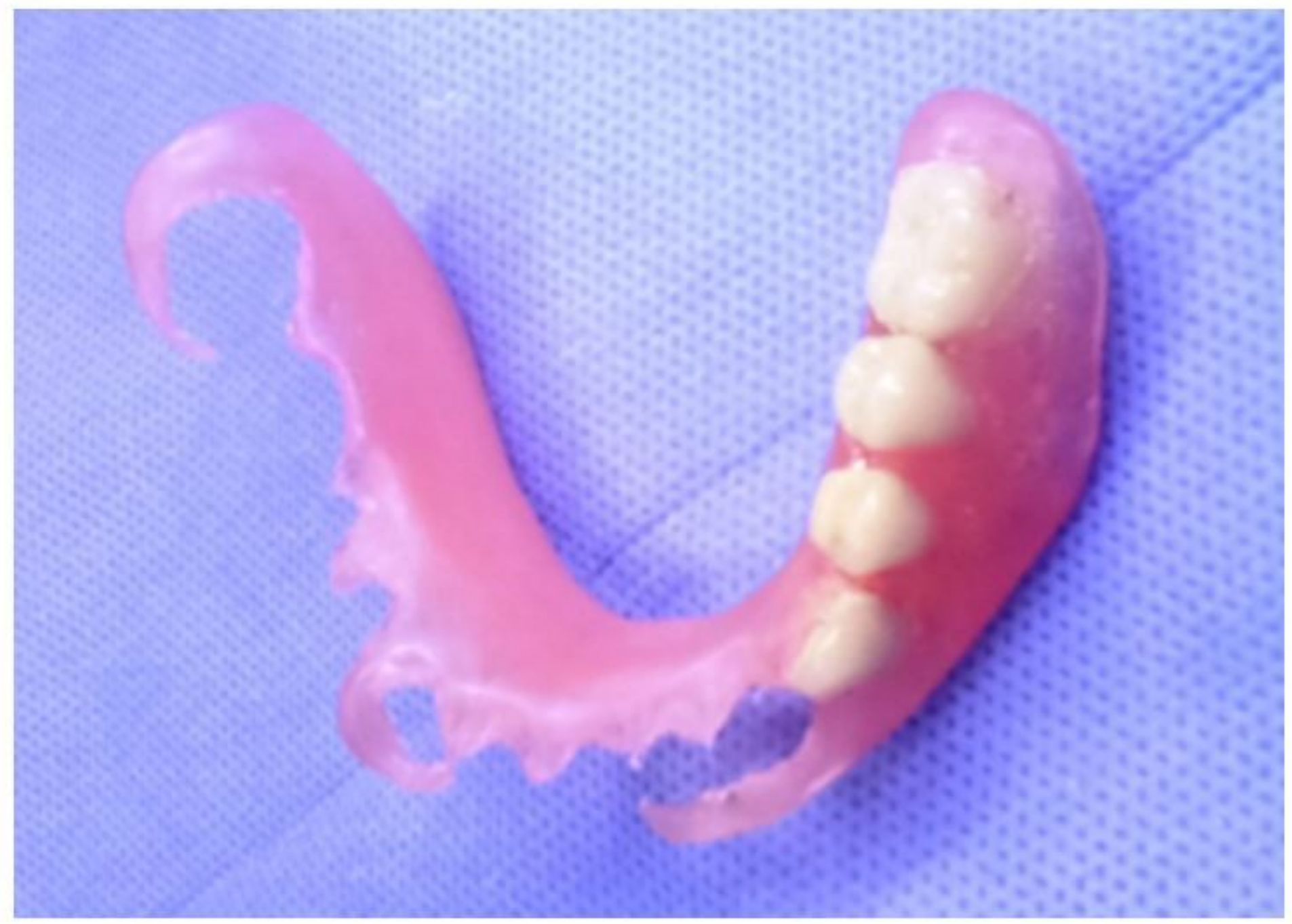

Figure 7

The flexible denture 


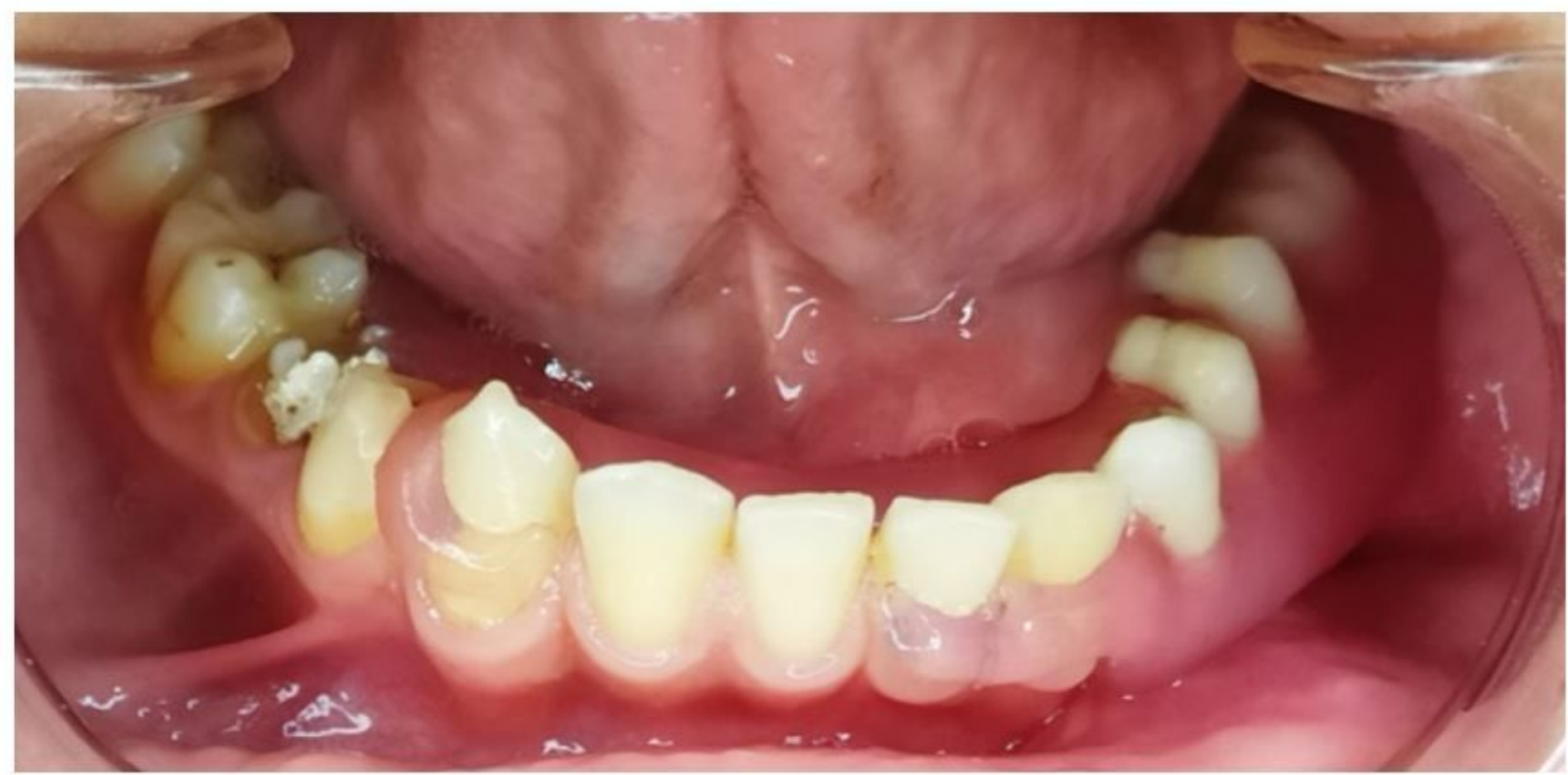

\section{Figure 8}

Flexible dentures inside the mouth

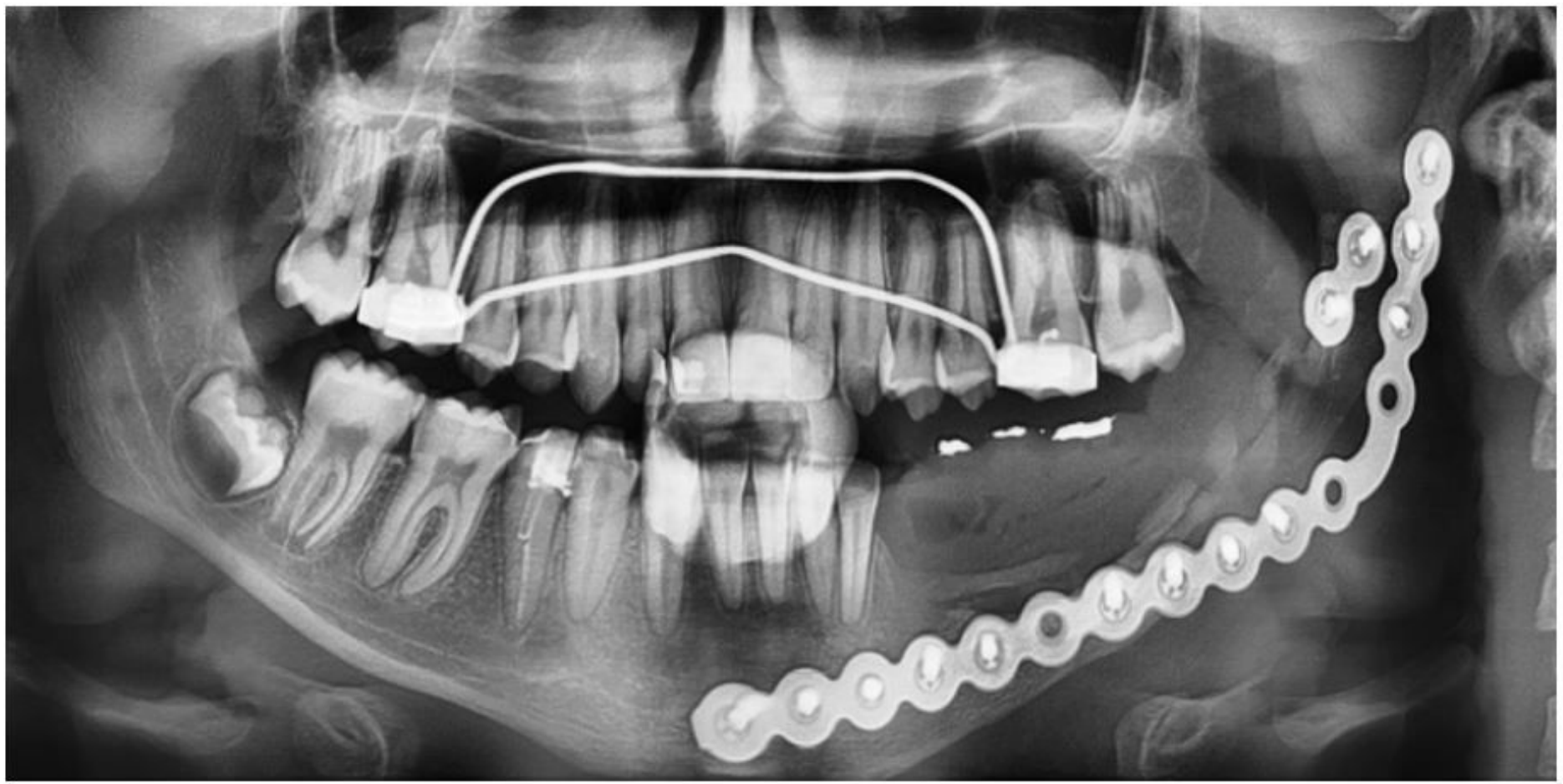

Figure 9

A radiographic image after denture delivery. 


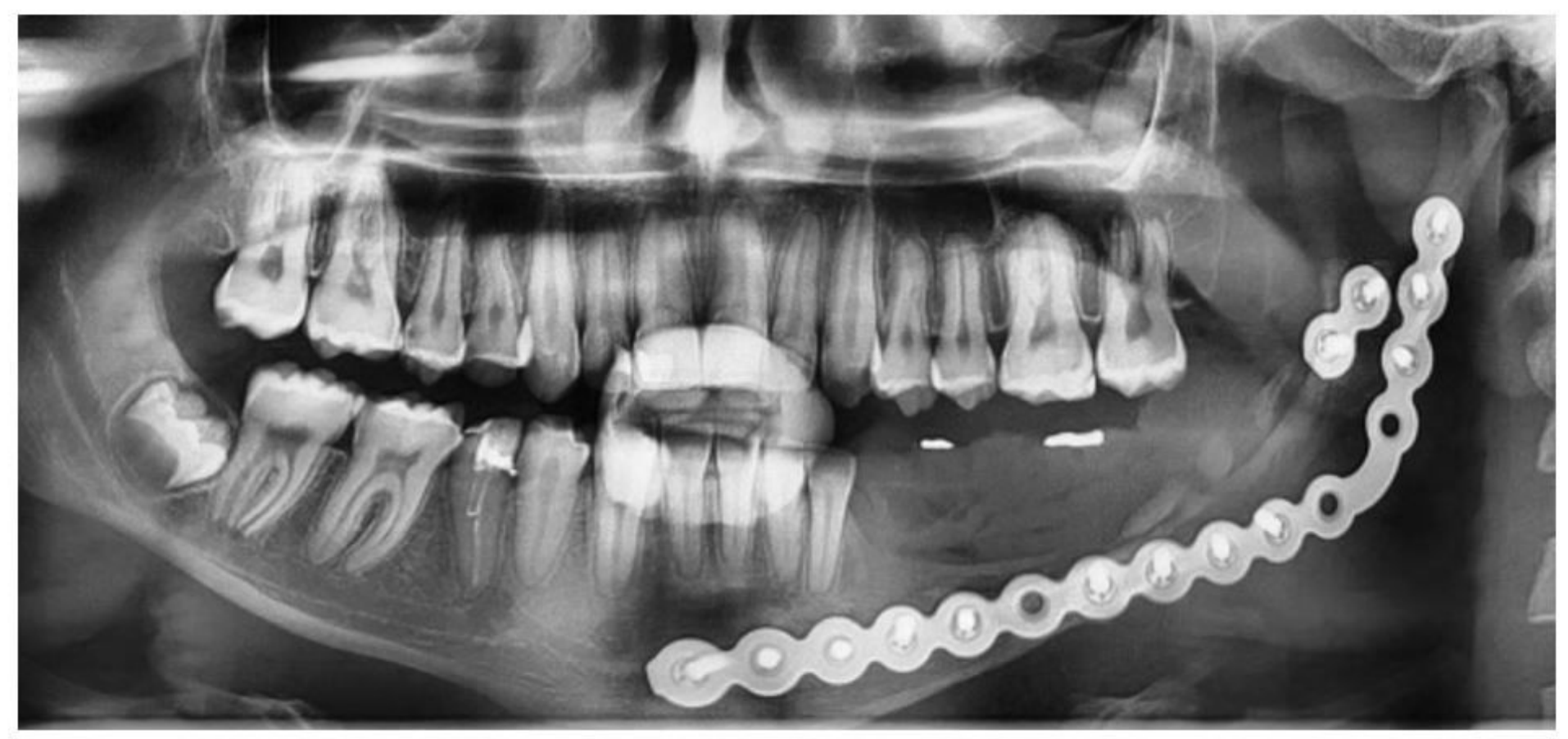

Figure 10

After 9 months. 